\title{
The influence of biliary constituents in an acid medium on the micellar solubilization of unesterified fatty acids of the duodenal digesta of sheep
}

\author{
BY AILEEN M. SCOTT AND A. K. LOUGH \\ Rowett Research Institute, Bucksburn, Aberdeen $A B 29 S B$
}

(Received I6 fuly 1970-Accepted 8 October I970)

\begin{abstract}
I. Duodenal contents were collected from cannulated sheep that were fed on dried grass cubes. After high-speed centrifugation, the distribution of long-chain unesterified fatty acids between the aqueous and particulate fractions of the digesta was examined.

2. The unesterified fatty acids of the digesta were found to be predominantly associated with the particulate matter.

3. When gall-bladder bile was added to the digesta at $37^{\circ}$ and $\mathrm{pH} 4.0$, in vitro, it was observed that unesterified fatty acids were transferred from the particulate matter to micellar solution. This transfer was due largely to the solubilizing effect of bile salts acting together with biliary phospholipids.

4. These findings are discussed in relation to the absorption of unesterified fatty acids by the sheep.
\end{abstract}

In sheep given normal diets, ingested lipids are hydrolysed and the resultant long-chain unsaturated fatty acids are hydrogenated by micro-organisms in the rumen. Thus a feature of the lipids in post rumen digesta of sheep is the preponderance of unesterified fatty acids of which stearic, palmitic and octadecenoic acids are the main constituents (see Garton, I967).

Experiments using sheep provided with double re-entrant cannulas in the small intestine showed that, by the time the digesta reached the ileum (i.e. the distal half of the small intestine), the uptake of fatty acids was almost complete. Furthermore, it was observed that, of the total unesterified fatty acids absorbed from the intestine, a small proportion was taken up from the upper jejunum where the digesta are acidic, with $\mathrm{pH}$ values ranging from $2 \cdot 8$ to $5 \cdot 0$ (Lennox \& Garton, 1968).

Because long-chain saturated fatty acids and their sodium salts are virtually insoluble in water at physiological temperatures (John \& McBain, 1948; McBain \& Sierichs, I948), it would appear likely that the formation of mixed micelles of bile salts and fatty acids is a prerequisite for fatty acid absorption to occur. However, Hofmann (I966) suggested that ionization of fatty acids was possibly of importance for their micellar solubilization in the lumen of the intestine. An examination was therefore made of the effects of whole bile and of certain biliary components, under acid conditions, on the duodenal contents of sheep.

A preliminary account of this investigation has previously been reported (Scott \& Lough, 1969). 


\section{EXPERIMENTAL AND RESULTS}

\section{Materials and analytical methods}

Biliary components. Sheep gall-bladder bile was obtained from the slaughter-house. A pooled sample $\left(55^{8} \mathrm{ml}\right)$ of bile from the gall-bladders of twenty-three adult sheep was freeze-dried and stored under $\mathrm{N}_{2}$ at $-20^{\circ}$. Samples of freeze-dried bile were reconstituted, as required, by the addition of distilled water. A portion of freeze-dried bile corresponding to $100 \mathrm{ml}$ fresh bile was analysed as previously reported (Lennox, Lough \& Garton, I968) for its content of lipids and bile salts (Table I).

A separate sample of pooled gall-bladder bile was used as a source of phosphatidylcholine (lecithin) and lysophosphatidylcholine (lysolecithin), which were isolated according to Lennox et al. (1968).

\section{Table I. Main lipid constituents of pooled gall-bladder bile from twenty-three adult sheep}

\begin{tabular}{lc}
\multicolumn{1}{c}{ Lipid } & $\begin{array}{c}\text { Amount } \\
\text { (mg/roo ml bile) }\end{array}$ \\
Neutral lipids & \\
Unesterified fatty acids & 76 \\
Esterified fatty acids & 30 \\
Total cholesterol & 74 \\
Phospholipids & \\
Lecithin & 885 \\
Lysolecithin & 255 \\
Total bile salts & 7840
\end{tabular}

Sodium taurocholate was obtained from Maybridge Research Chemicals, Tintagel; thin-layer chromatography revealed only traces of impurities.

Duodenal digesta. In a manner similar to that described by Lennox \& Garton (I968), six adult sheep provided with re-entrant cannulas immediately distal to the pylorus were given daily a diet of $800 \mathrm{~g}$ pelleted dried grass from a continuous feed-delivery device. Samples of digesta were collected over periods of $3^{-6} \mathrm{~h}$. To ensure that the digesta were uncontaminated with biliary and pancreatic secretions, the first $250 \mathrm{ml}$ of each collection were discarded. For a number of experiments the digesta were first heated in a boiling water-bath for $\mathrm{I} h$ to inactivate enzymes; otherwise they were used as collected. The $\mathrm{pH}$ value of each sample of digesta was within the range $2 \cdot 5^{-2} \cdot 8$.

The specific gravity of the clear fluid obtained by the centrifugation of duodenal digesta for $30 \mathrm{~min}$ at $60000 \mathrm{~g}$ was determined with a pycnometer. In two determinations the value $d_{20}^{20}$ r.006 was observed.

Solubilization experiments. These were carried out using duodenal digesta and either gall-bladder bile or aqueous solutions of taurocholate with and without biliary phospholipids at $\mathrm{pH} 4.0$ and $37^{\circ}$.

Duodenal contents $(8 \mathrm{ml})$ were mixed, in a $15 \mathrm{ml}$ Spinco tube, with bile or with aqueous solutions of biliary components $(2 \mathrm{ml})$ and the tubes were shaken at $37^{\circ}$ and $\mathrm{pH} 4 \cdot 0$ (adjusted by the addition of solid $\mathrm{NaHCO}_{3}$ ) for varying periods up to $24 \mathrm{~h}$. 
After incubation the tubes were centrifuged at $60000 \mathrm{~g}$ for $30 \mathrm{~min}$ and the supernatant and sedimented fractions were separately analysed for unesterified fatty acids.

In experiments in which duodenal contents were repeatedly treated with solutions of bile salt-lecithin mixtures, the amount of decanted fluid (after centrifuging) was replaced, on each occasion, with an equal volume of $0.9 \% \mathrm{NaCl}$ solution. The adjustment of $\mathrm{pH}$ was thereafter made by titration with $\mathrm{HCl}$ or $\mathrm{NaOH}$ solution.

Analysis of unesterified fatty acids. Samples of fractionated and unfractionated digesta were extracted with chloroform-methanol ( $\mathrm{I}: \mathrm{I} \mathrm{v} / \mathrm{v}$ ), using $\mathrm{x}$ o $\mathrm{ml}$ solvent/g sample, by heating under reflux for $15 \mathrm{~min}$. Nonadecanoic acid ( $94 \%$ pure) was usually added to the extracts in known amount as an internal standard and the extracts were filtered or centrifuged. The lipids obtained from these extracts were treated with diazomethane according to the procedure of Schlenk \& Gellerman (1960) and the fatty acids thus methylated were freed of more polar lipid material by adsorption on silicic acid (Mallinckrodt) in the presence of chloroform. Methyl esters of long-chain fatty acids were analysed on a Pye Argon Chromatograph at $185^{\circ}$ using $\mathrm{x} \cdot 2 \mathrm{~m} \times 4 \mathrm{~mm}$ columns packed with $15 \%$ polymerized ethylene glycol succinate or $7.5 \%$ Apiezon $L$ on Celite 545 (80/100 mesh).

The amount of unesterified fatty acids was estimated from the gas chromatograms by relating the areas under the peaks representing the fatty acid components to that of the internal standard. Using nonadecanoate there was little or no superimposition of the standard with any of the fatty acid components resolved on the polar phase except when linoleate was present, as in the experiments involving bile. However, the latter difficulty was obviated by chromatographing the mixture of esters on the non-polar phase.

In the estimation of the fatty acid content of the solid phase of the digesta due allowance was made, on the basis of moisture content, for inclusion of micellar solution with the particulate matter. It was assumed that the error resulting from the adsorption of water to the particulate surfaces was negligible since the amount of adsorbed water was likely to be small compared with the volume of micellar solution retained by capillary attraction.

\section{Unesterified fatty acids in the solid and liquid fractions of duodenal digesta}

The distribution of unesterified fatty acids between the particulate and supernatant fractions of fresh (unheated) duodenal digesta is shown in Table 2.

In Table 2 the results of analyses of digesta from three sheep show a marked preponderance of fatty acids in the sedimented fraction, thus indicating that they were associated with the particulate fraction. However, stearic acid accounted for over $75 \%$ of the unesterified fatty acids in the digesta and, since one of the crystalline forms of the acid, namely the B-form, has a density of about I·O4-I·O5 (Müller, I929; O'Connor, I960), it is possible that stearic acid in this free form might be present in the particulate fraction. The specific gravity of the aqueous medium was therefore increased from $\mathrm{I} \cdot 006_{20}^{20}$ to $>\mathrm{I} \cdot 06$ by the addition of sucrose $(\mathrm{I} \cdot 8 \mathrm{~g}$ sucrose to $\mathrm{I} \cdot .0 \mathrm{ml}$ digesta).

A comparison was made of the distribution of unesterified fatty acids between the supernatant and the particulate fractions of unheated duodenal digesta and of the same 
sample of digesta to which sucrose had been added. The results of this experiment are shown in Table 3 which indicates that the amount of unesterified fatty acids which sedimented at $60000 \mathrm{~g}$ in a medium of specific gravity $>\mathrm{r} .06$ was only slightly less than that which sedimented in normal intestinal contents. Furthermore, the fatty acid composition of the supernatant fraction resulting from centrifuging the digesta containing added sucrose was similar to that of the control sample.

Thus the greater proportion of unesterified fatty acids of duodenal digesta from sheep given grass is associated with the particulate matter.

The form in which the small amount of unesterified fatty acids exists in the supernatant fraction is not known.

Table 2. Amounts of unesterified fatty acids in the supernatant and particulate fractions of duodenal digesta (1o $\mathrm{ml}$ ) from three grass-fed sheep

(Means of duplicate estimations)

\begin{tabular}{|c|c|}
\hline \multicolumn{2}{|c|}{ Weight of fatty acid (mg) } \\
\hline Particulate fraction & Supernatant fraction \\
\hline II $\cdot 7$ & $0 . I$ \\
\hline 12.8 & 0.3 \\
\hline 10.4 & 0.3 \\
\hline
\end{tabular}

Table 3. Effect of increasing the density of the aqueous medium on the distribution of unesterified fatty acids between the particulate and supernatant fractions of duodenal digesta obtained from two sheep and pooled

\begin{tabular}{|c|c|c|c|c|c|}
\hline \multicolumn{6}{|c|}{ (Means of duplicate estimations) } \\
\hline & & \multicolumn{4}{|c|}{ Unesterified fatty acids } \\
\hline \multirow[t]{2}{*}{$d_{20}^{20}$} & \multirow[t]{2}{*}{ Fraction } & \multirow[t]{2}{*}{$\begin{array}{c}\text { Weight } \\
\text { (mg/ro ml digesta) }\end{array}$} & \multicolumn{3}{|c|}{$\begin{array}{c}\text { Composition } \\
\text { (\% wt of } \mathrm{C}_{16} \text { and } \mathrm{C}_{18} \text { acids) }\end{array}$} \\
\hline & & & $16: 0$ & $18: 0$ & I8: I \\
\hline \multirow[t]{2}{*}{ I.006 } & Supernatant & 0.2 & 12 & 72 & 16 \\
\hline & Particulate & $10 \cdot 6$ & 10 & 76 & 14 \\
\hline \multirow{2}{*}{$>\mathbf{I} \cdot 06$} & Supernatant & 0.8 & II & 74 & I5 \\
\hline & Particulate & 10.0 & IO & 76 & 14 \\
\hline
\end{tabular}

\section{Solubilization experiments}

When bile ( $\mathrm{I}$ vol.) was added to heat-inactivated duodenal digesta $(4$ vol.) at $\mathrm{pH} 4 . \circ$ and $37^{\circ}$, unesterified fatty acids were progressively transferred from association with the particulate matter into solution in the liquid phase. More than half of the unesterified fatty acids originally associated with the solid phase of the digesta was solubilized at equilibrium, which was reached within $90 \mathrm{~min}$ (excluding the period of $30 \mathrm{~min}$ for centrifugation).

Using a sample of heat-inactivated duodenal digesta, it was observed that, of II. $37 \pm 0.45 \mathrm{mg}$ unesterified fatty acid originally associated with the solid phase of Io $\mathrm{ml}$ digesta, about $60 \%$ were transferred into micellar solution in the presence of bile at $\mathrm{pH} 4.0$ (Table 4 ). 
To determine the effect of some of the constituents of bile on solubilization, duodenal digesta (Io $\mathrm{ml}$ portions) were treated, in separate experiments, with a solution $(2.5 \mathrm{ml})$ of taurocholate $(196 \mathrm{mg}$ ) either alone or with biliary lecithin $(22 \cdot 1 \mathrm{mg})$ or lysolecithin $(6.4 \mathrm{mg})$ or both. These concentrations correspond to those shown in Table I (taurocholate $\equiv$ total bile salt); maximal solubilization of fatty acids was attained within $90 \mathrm{~min}$; the respective amounts of solubilized fatty acids are shown in Table 4.

Table 4. Net amount of unesterified fatty acids transferred into micellar solution (at $37^{\circ}$ and $\mathrm{pH}_{4}{ }^{\circ} \mathrm{O}$ ) from association with the particulate matter of sheep duodenal digesta (1० $\mathrm{ml}$ ) by the addition of bile or of aqueous solutions of bile salt or biliary phospholipids or both

Treatment
Bile
Taurocholate + lecithin + lysolecithin
Taurocholate + lecithin
Taurocholate + lysolecithin
Taurocholate

Weight of unesterified fatty acids $(\mathrm{mg}) \quad$ SD

$\begin{array}{ll}7.00(9) & 0.50 \\ 5.67(\mathrm{IO}) & 0.39 \\ 5.14 \text { (10) } & 0.32 \\ 3.41(8) & 0.22 \\ 1.90(9) & 0.22\end{array}$

No. of estimations in parentheses.

In relation to the net amount of fatty acids solubilized in the presence of whole bile, the proportion of fatty acids taken into solution when bile salt alone was added to duodenal digesta was about $30 \%$; the addition of lecithin increased this to $70 \%$. Corresponding values for lysolecithin and for lecithin plus lysolecithin were 50 and $80 \%$ respectively. It should, however, be noted that the results shown in Table 4 represent, in each instance, the net amount of fatty acids transferred into solution and not necessarily the total amount of fatty acids in micellar solution. Thus, in the experiment in which bile was added to duodenal digesta, the total amount of fatty acids in solution comprised the net amount transferred from the solid digesta together with the amount of acids originally present in the bile itself (Table I). On the basis of the total amounts of fatty acid in the solubilized form, it would appear that under the experimental conditions whole bile is capable of maintaining in micellar solution about half as much again of the amount of fatty acid solubilized by the combined action of bile salt, lecithin and lysolecithin.

In Table 5 the composition of the major fatty acids solubilized by whole bile and by the respective bile salt-phospholipid solutions is presented together with that of the unesterified fatty acids originally associated with the digesta; all these results were obtained in the same experiment from which the observations shown in Table 4 were derived. Concerning the solubilization experiments employing whole bile, allowance was made for the amount and composition of the unesterified fatty acids originally present in the sample of bile.

It can be seen from Table 5 that, in general, the fatty acid composition of each micellar solution resembled that of the acids in the untreated digesta. In every instance the amount of stearic acid taken into solution greatly exceeded that of the other component acids. However, in terms of the proportions of each acid initially present on the solid phase of duodenal digesta, it is clear that in the presence of bile and of the 
respective bile salt-phospholipid solutions no marked preference for the solubilization of any individual acid was observed. If, as can be presumed, the $\mathrm{C}_{18}$ monoene fraction represents a mixture of octadecenoic acids, the possibility that some form of preferential solubility may exist among the various isomers cannot be precluded; the method of fatty acid analysis employed in this investigation did not permit the resolution of the $\mathrm{C}_{18}$ monoethenoid acids likely to be encountered.

Finally, a series of experiments was carried out to determine the extent to which unesterified fatty acid can be removed from association with the particulate fraction of digesta by successive treatments of the solid phase with solutions of bile salt-lecithin.

Table 5. Composition of fatty acids associated with the particulate matter of duodenal digesta and of fatty acids transferred from this particulate fraction into micellar solution at $37^{\circ}$ and $p H 4.0$ by sheep bile or bile salt-phospholipid solutions

\begin{tabular}{|c|c|c|c|}
\hline \multirow[b]{2}{*}{ Origin of fatty acids } & \multicolumn{3}{|c|}{$\begin{array}{c}\text { Fatty acid composition } \\
\text { (\% wt of } \mathrm{C}_{16} \text { and } \mathrm{C}_{18} \text { acids) }\end{array}$} \\
\hline & $16: 0$ & $18: 0$ & $18: x$ \\
\hline matter & 9 & 77 & 14 \\
\hline & 14 & 70 & 16 \\
\hline late + lecithin + lysolecithin & IO & 70 & 20 \\
\hline ate +lecithin & I I & 67 & 22 \\
\hline olate + lysolecithin & 9 & 65 & 26 \\
\hline
\end{tabular}

Table 6. Amount of unesterified fatty acids associated with the particulate fraction of sheep duodenal digesta $(1 \circ \mathrm{ml})$ before and after repeated treatment with aqueous solutions $(2 \cdot 5 \mathrm{ml})$, containing taurocholate (196 mg) and bile lecithin (22.1 $\mathrm{mg})$, for $90 \mathrm{~min}$ at $37^{\circ}$ and $p \mathrm{H}_{4 \cdot 0}$

(Means of duplicate estimations)

$\begin{array}{cc}\text { No. of treatments } & \text { Weight of unesterified fatty acids (mg) } \\ 0 & 15.9 \\ \text { I } & 10.4 \\ 2 & 6.0 \\ 3 & 3.0 \\ 4 & 1.4 \\ 5 & 0.5\end{array}$

The results from an experiment using heat-treated digesta are shown in Table 6. Duodenal digesta (4 vol.), which were taken from a pooled sample of collections from two sheep, were treated successively with bile salt-lecithin solution (I vol.) in concentrations simulating those which occur in bile (Table r). After only three treatments at $\mathrm{pH}_{4} \circ$, about $80 \%$ of the total unesterified fatty acids in the digesta was solubilized, and after five treatments less than $5 \%$ of the total remained in association with the particulate fraction.

The amounts of unesterified fatty acids taken into micellar solution in the first three treatments with bile salt-lecithin were respectively $5.5,4.4$ and $3.0 \mathrm{mg}$. Since each treatment was carried out under identical conditions of time, temperature and $\mathrm{pH}$, the decrease observed in the amounts of solubilized fatty acids at each stage of the experi- 
ment suggests that there may have been a corresponding decrease in the amount of amphiphile contributed by the digesta itself or that the unesterified fatty acids of the digesta were not uniformly accessible to the detergent action of the biliary components, or that both these processes may have occurred.

Similar experiments were carried out using fresh unheated digesta, except that the incubations were conducted in the $\mathrm{pH}$ range $7-8$ to minimize pepsin activity. To obtain the same degree of solubilization noted above, fewer treatments with bile salt-lecithin solutions were required because of the increased capacity of bile saltlecithin to solubilize fatty acids at higher $\mathrm{pH}$.

\section{DISCUSSION}

The results have shown that, in duodenal digesta from sheep, the unesterified fatty acid fraction, which comprises mainly stearic, palmitic and octadecenoic acids, is predominantly associated with the particulate matter of the digesta. In the presence of bile, unesterified fatty acids are transferred from association with the solid phase of the digesta into micellar solution. This transfer can proceed virtually to completion, in vitro, by repeated exposure of the digesta to the concerted action of bile salts and biliary phospholipids even under the markedly acidic conditions such as exist in the upper jejunal lumen of the sheep.

The observation that bile can effect the micellar solubilization of unesterified fatty acid is undoubtedly relevant to the findings of Heath \& Morris (1963) who reported that, when bile flow is diverted from the small intestine of the sheep, lipid absorption is almost completely abolished. In this connexion, the combination of bile salt and phospholipid offers the particular advantages of readily taking stearic acid into micellar solution, and of providing a system of fatty acid solubilization that is effective throughout the range of luminal $\mathrm{pH}$.

Although Hofmann (1966) suggested that ionization of fatty acids may be a prerequisite for their micellar solubilization in association with bile salts, the results of our experiments carried out at $\mathrm{pH}_{4} \cdot 0$ indicate that fatty acids in the un-ionized form can be rendered soluble to a measurable extent. That the function of bile salt-lecithin-water as a system for the solubilization of cholesterol could extend to other non-swelling amphiphiles, such as un-ionized fatty acids, was suggested by Small (1968), who also indicated that lysolecithin can participate in the formation of mixed micelles with bile salts and lecithin.

Possible mechanisms whereby fatty acids of sheep duodenal digesta become associated with phospholipids and bile salts in solutions of mixed micelles have been discussed (Lough, 1970). Detergency is undoubtedly involved and it is envisaged that isotropic micellar solutions result from the interaction of liquid-crystalline phase, composed of fatty acid and phospholipid, with bile salts in the presence of water.

Though lecithin and lysolecithin of biliary origin are the main phospholipid components in the intestinal lumen of the sheep, it seems that phospholipid originating in the digesta itself will augment the solubilizing effect of bile. This likelihood is supported by the observation that some $30 \%$ of the unesterified fatty acid solubilized 
in the presence of bile at $\mathrm{pH} 4.0$ could be accounted for by the addition of bile salt alone. Also it has been observed that greater amounts of unesterified fatty acids were solubilized when bile salt alone was added to duodenal digesta containing its full complement of lipids as compared with digesta from which the phospholipid fraction had previously been removed (A. K. Lough, unpublished observations). In this connexion it is noteworthy that phosphatidylethanolamine, which constitutes a substantial proportion of the polar lipids of rumen micro-organisms (Kunsman, I966), is virtually isoelectric at about $\mathrm{pH} 4$ (Bangham, I968) and therefore may be expected to exhibit physical properties somewhat similar to those of lecithin under these acidic conditions.

Though the unesterified fatty acids of duodenal digesta are mainly associated with the particulate matter, the form or forms of association are not known. Sedimentation of fatty acid through a medium of specific gravity $>\mathrm{I} \cdot 06$ provided unequivocal evidence that stearic acid, for example, must be associated with the solid phase of duodenal digesta but gives no indication of the nature of this association. However, it has been suggested that stearic acid formed by hydrogenation in the rumen becomes attached to feed particles (Ward, Scott \& Dawson, 1964). It is likely that unesterified fatty acids may be adsorbed on cell surfaces, such as those of bacteria (Kodicek, I949; Nieman, 1954; Maxcy \& Dill, 1967).

The observation that virtually all of the fatty acid associated with the particulate fraction of duodenal digesta can be removed by repeated treatments with bile saltphospholipid solutions lends further support to the supposition that fatty acids are adsorbed to the surfaces of the solid matter. Nevertheless, the possibility that unesterified fatty acids of the contents of the intestinal lumen may exist in some form of complex with protein cannot be precluded, since detergent solutions are known to disrupt lipid-protein associations in plasma and membranes to yield 'free' lipid (Dervichian, 1964; Salton \& Schmitt, 1967; Simons \& Helenius, 1970).

Some form of binding of fatty acid (by protein, for example) in duodenal digesta has been envisaged by Leat \& Harrison ( 1969 ), who found that there was no redistribution of unesterified fatty acids between the solid and liquid phases of jejunal contents when the $\mathrm{pH}$ was adjusted to about $\mathrm{pH} 8$, though solubilization of fatty acids did occur following incubation of the digesta for $3 \mathrm{~h}$ at $\mathrm{pH} \mathrm{6.5}$. While binding of fatty acids to other digesta is not entirely precluded, it nevertheless appears from our studies that direct solubilization is probably of prime importance. The effect of proteolytic enzymes on intraluminal events as they affect fatty acids is, however, only one of the many aspects of lipid digestion which must await further investigation.

The authors wish to thank Dr G. A. Garton for his interest and helpful criticism, Dr R. N. B. Kay for kindly making available the cannulated sheep, and Miss Norma Amos for her technical assistance. 


\section{REFERENCES}

Bangham, A. D. (1968). Prog. Biophys. molec. Biol. 18, 29.

Dervichian, D. G. (1964). Prog. Biophys. molec. Biol. 14, 263.

Garton, G. A. (1967). Wld Rev. Nutr. Diet. 7, 225.

Heath, T. J. \& Morris, B. (1963). Br. F. Nutr. 17, 465 .

Hofmann, A. F. (1966). Gastroenterology 50, 56.

John, L. M. \& McBain, J. W. (1948). Ұ. Am. Oil Chem. Soc. 25, 4 o.

Kodicek, E. (1949). Symp. Soc. exp. Biol. 3, 217.

Kunsman, J. E. (1966). Characterization of the lipids from pure cultures of rumen bacteria. PhD Thesis, University of Maryland.

Leat, W. M. F. \& Harrison, F. A. (1969). Q. $\Re l$ exp. Physiol. 54, I87.

Lennox, A. M. \& Garton, G. A. (x968). Br. F. Nutr. 22, 247.

Lennox, A. M., Lough, A. K. \& Garton, G. A. (1968). Br. F. Nutr. 22, 237.

Lough, A. K. (1970). In Physiology of Digestion and Metabolism in the Ruminant p. 5 19 [A. T. Phillipson, editor]. Newcastle upon Tyne: Oriel Press Ltd.

McBain, J. W. \& Sierichs, W. C. (1948). F. Am. Oil Chem. Soc. 25, 221.

Maxcy, R. B. \& Dill, C. W. (1957). F. Dairy Sci. 50, 472.

Müller, A. (1929). Proc. R. Soc. A II4, 542.

Nieman, C. (1954). Bact. Rev. r8, 147.

O'Connor, R. 'T. (1960). In Fatty Acids and ed., Part r, p. 285 [K. S. Markley, editor]. New York: Interscience.

Salton, M. R. J. \& Schmitt, M. D. (1967). Biochem. biophys. Res. Commun. 27, 529.

Schlenk, H. \& Gellerman, J. L. (1960). Analyt. Chem. 32, 1412.

Scott, A. M. \& Lough, A. K. (1969). Biochem. F. Ir3, 28 P.

Simons, K. \& Helenius, A. (1970). FEBS Lett. 7, 59.

Small, D. M. (1968). F. Am. Oil Chem. Soc. 45, 108.

Ward, P. F. V., Scott, T. W. \& Dawson, R. M. C. (1964). Biochem. J. 92, 60. 